\title{
Laparoscopic Incisional Hernia Repair
}

\author{
Anita Kurmann and Guido Beldi \\ Department of Visceral Surgery and Medicine, Bern University Hospital \\ University of Bern, Bern \\ Switzerland
}

\section{Introduction}

An incisional hernia (Fig 1.) is defined as any abdominal wall gap with or without a bulge in the area of a postoperative scar perceptible or palpable by clinical examination or imaging [1]. Incisional hernia is a common long-term complication following abdominal surgery and is estimated to occur in $11-23 \%$ [2, 3]. Risk factors for incisional hernia are male gender, body mass index, cancer, and previous laparotomy $[4,5]$.

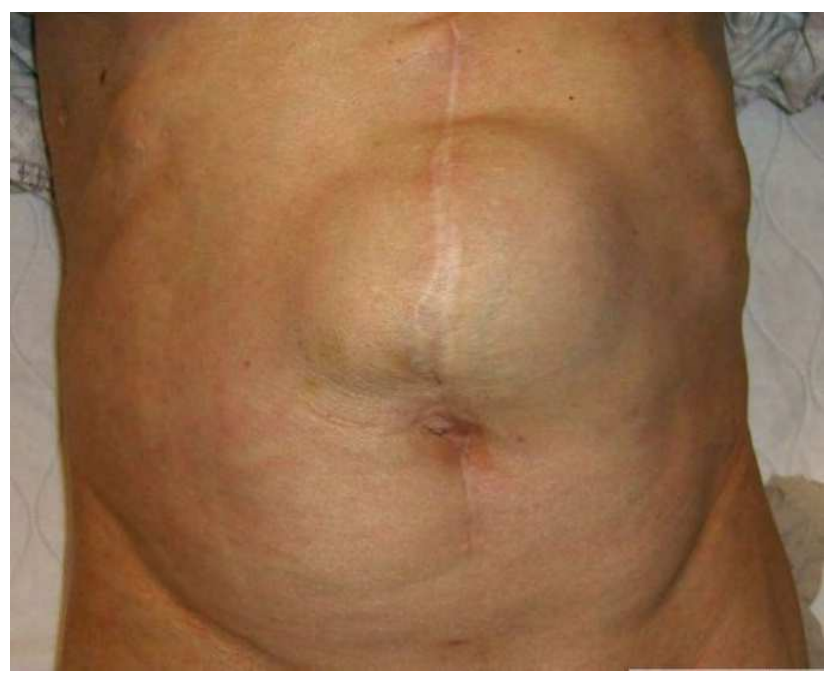

Fig. 1. Clinical presentation of a patient with a large incisional hernia

Conventional hernia repair with tissue approximation was associated with a recurrence rate of $60 \%$. Theodore Billroths vision was the source of changes in hernia repair. Billroth told to his pupil Cerny: "If we could artificially produce tissues of the density and toughness of fascia and tendon the secret of the radical cure of hernia would be discovered". This statement appeard in the classic Beiträge zur Chirurgie in 1987. Francic C. Usher introduced 1957 a polypropylene based prosthesis to bridge the hernia defect and to reinforce the abdominal wall without tension [6]. With the implantation of prosthesis the recurrence rate in hernia repair was downsized [7]. 
Incisional hernia can be repaired by open or by laparoscopic approach and prosthetic meshes are nowadays implanted in most procedures. The use of laparoscopy for the treatment of incisional hernia was first reported in 1993 by LeBlanc and Booth [8]. With the introduction of modern two-layered mesh, laparoscopic incisional hernia repair has become an accepted therapeutic option. Feasibility and safety of laparoscopic incisional hernia repair has been shown in various randomized controlled trials.

\section{Incisional hernia classification}

Developing a good classification for incisional hernias is much more difficult than for groin hernias or for primary abdominal wall hernias because of their great diversity. The classification as established and published by the consensus meeting of the European Hernia Society held in Ghent, Belgium, 2008, (Tab 1.) comprises a division of subgroups for incisional hernia, including localization, width, and length of the hernia [9]. The use of the classification of the European Hernia Society is nowadays recommended. The analysis of subgroups may define patients with high risk for recurrences and may lead to specific treatment options. This classification is applicable in laparoscopic and open incisional hernia repair.

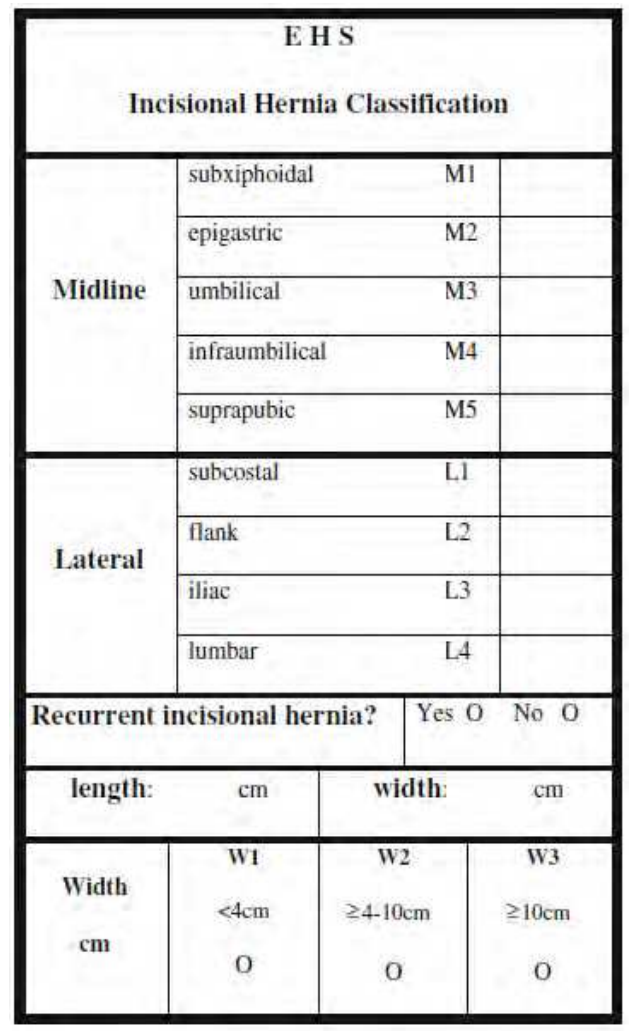

Table 1. European Hernia Society classification for incisional abdominal wall hernia 


\section{Symptoms}

A swelling or protrusion with or without abdominal pain can be observed in a patient with an incisional hernia when the patient sits up or coughs. In large incisional hernia peristaltic bowel movements can be observed through a thin skin, sometimes already accompanied with signs of a skin infection. Incisional hernias may occur along the full length of the incision with one or multiple hernial orifices. Incarceration is the main complication of an incisional hernia [10] and occurs in 1-3\% of all hernias. Signs of incarceration are acute pain and vomiting. Clinically there is a tense, tender irreducible hernia. In these cases an emergency hernia repair is mandatory. Emergency hernia repair can also be performed by laparoscopy with an additional mini-laparotomy if bowel resection is necessary.

Incisional hernia can be diagnosed by physical examination. Additional ultrasound or CTscan examination are recommended in cases of uncertainty (Fig 2).
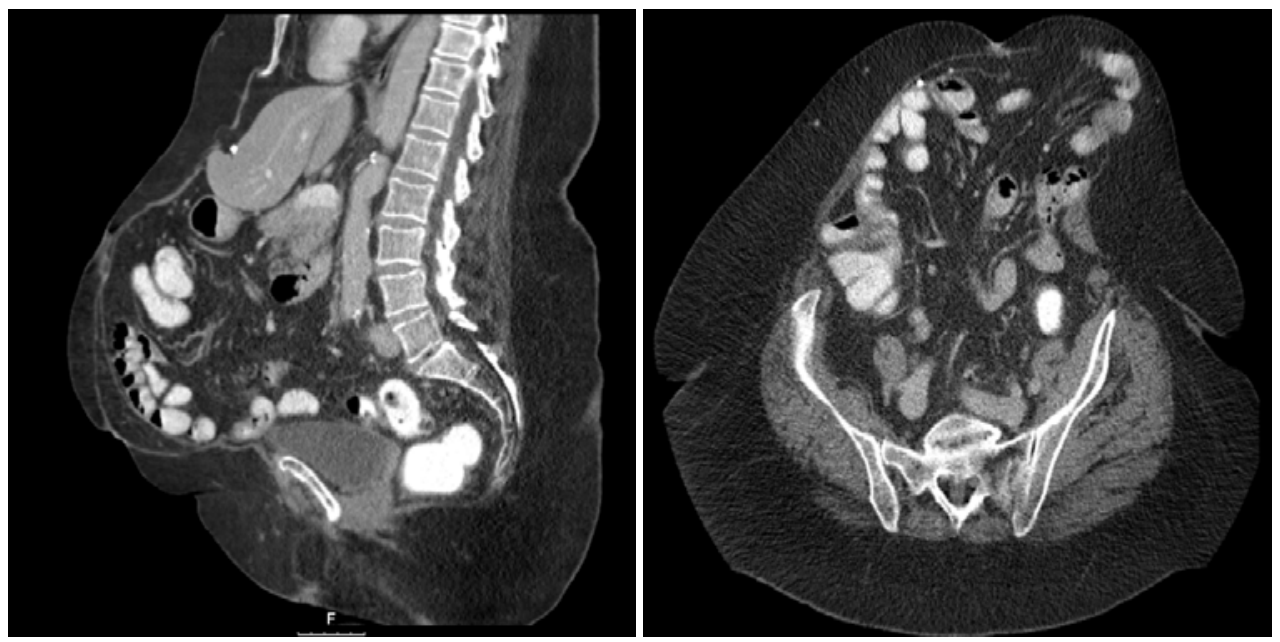

Fig. 2. CT-Scan of a patient with a large incisional hernia. The hernia contains small and large bowel.

\section{Surgical technique of laparoscopic hernia repair}

We routinely use a $30^{\circ}$ camera. Scissors and two graspers have to be prepared for laparoscopic hernia repair. The screen is placed at the opposite of the surgeon. The patient is placed in a supine position with both arms unabducted under general anesthesia. A single shot of antibiotics is given preoperatively. The site of trocar placing depends on the localization of the hernia. If the hernia is localized in the right hemiabdomen, the trocars should be placed on the left side. Using a limited open technique the pneumoperitoneum is established and the optical trocar is inserted, and under direct vision, a minimum of two additional trocars at a suitable distance from the hernial orifice are inserted. Alternatively the pneumoperitoneum can be established using a Verres-Needle. After establishing the pneumoperitoneum at $12 \mathrm{mmHg}$ a diagnostic laparoscopy is performed. Adhesions between the omentum or intestine with the anterior wall surrounding the hernial orifice are divided, and the content of the hernia is reduced completely (Fig. 3). Adhesiolysis has to be 
performed with scissors and without electocoagulation under direct vision to avoid bowel lesions. In cases of incarceration the necrotic tissue has to be resected. If there is not enough working space or the trocars are not correctly placed an additional trocar can be helpful.

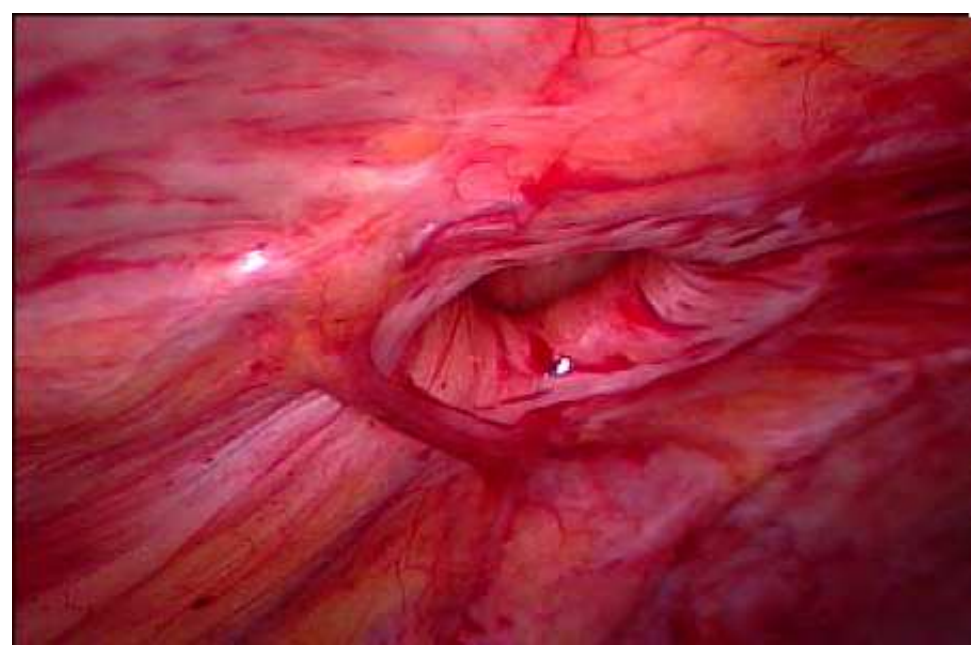

Fig. 3. Intraoperative laparoscopic view of the hernial orifice

In general, the hernial sac is left in situ. After completion of adhesiolysis, the pneumoperitoneum is released, the maximal longitudinal and horizontal hernia diameter is measured and marked on the skin (Fig. 4). An appropriate sized mesh is tailored in order to

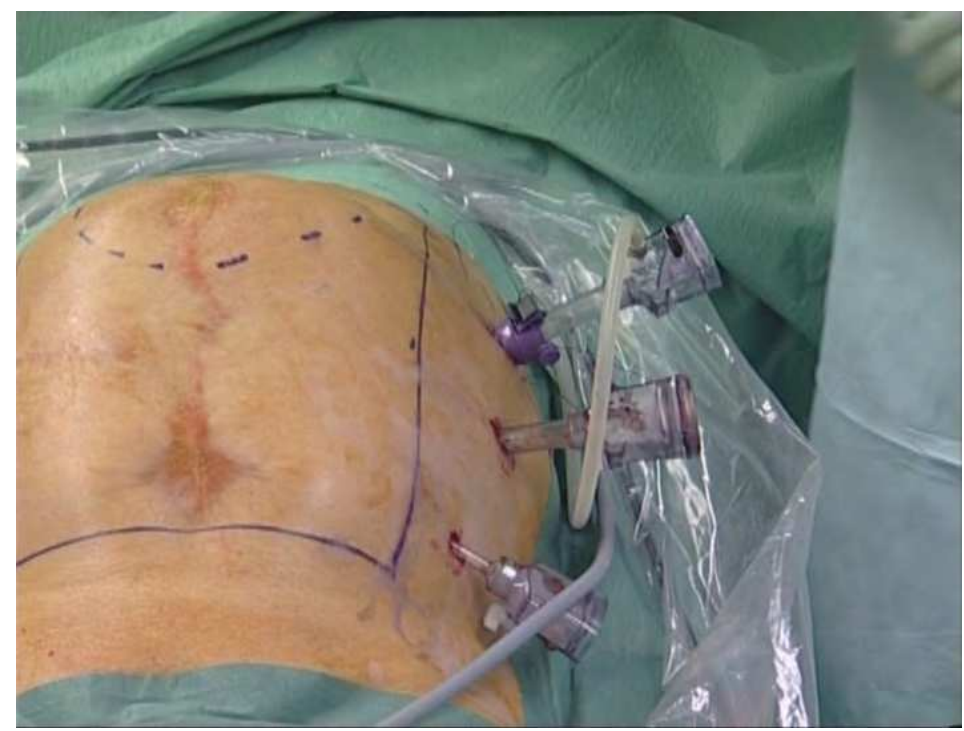

Fig. 4. Patient with an incisional hernia in the upper part of the scar. The hernia and the size of the mesh is marked on the patients skin. 
overlap the hernia margins by at least $5 \mathrm{~cm}$ on each side. In addition, the mesh should overlap the full length of the incision of the primary operation. Non absorbable monofilament sutures are placed in $2-3 \mathrm{~cm}$ intervals along the mesh margin. The mesh is rolled up and inserted into the abdomen through a $12 \mathrm{~mm}$ trocar.

Then the mesh is rolled up and introduced into the abdominal cavity. After the mesh is positioned correctly in the abdominal cavity, the suture ties are pulled through the abdominal wall with a suture passer and the threats are knotted smoothly with the knots buried in the subcutaneous tissue after reduction of the intraabdominal pressure to $8 \mathrm{mmHg}$. We use titanium tackers that are applied between the sutures every 1 to $2 \mathrm{~cm}$ between the sutures and around the hernial orifice (Fig 5). If the skin is necrotic or to enhance cosmetic results in large incisional hernia an additional open cutaneous excision is recommended.

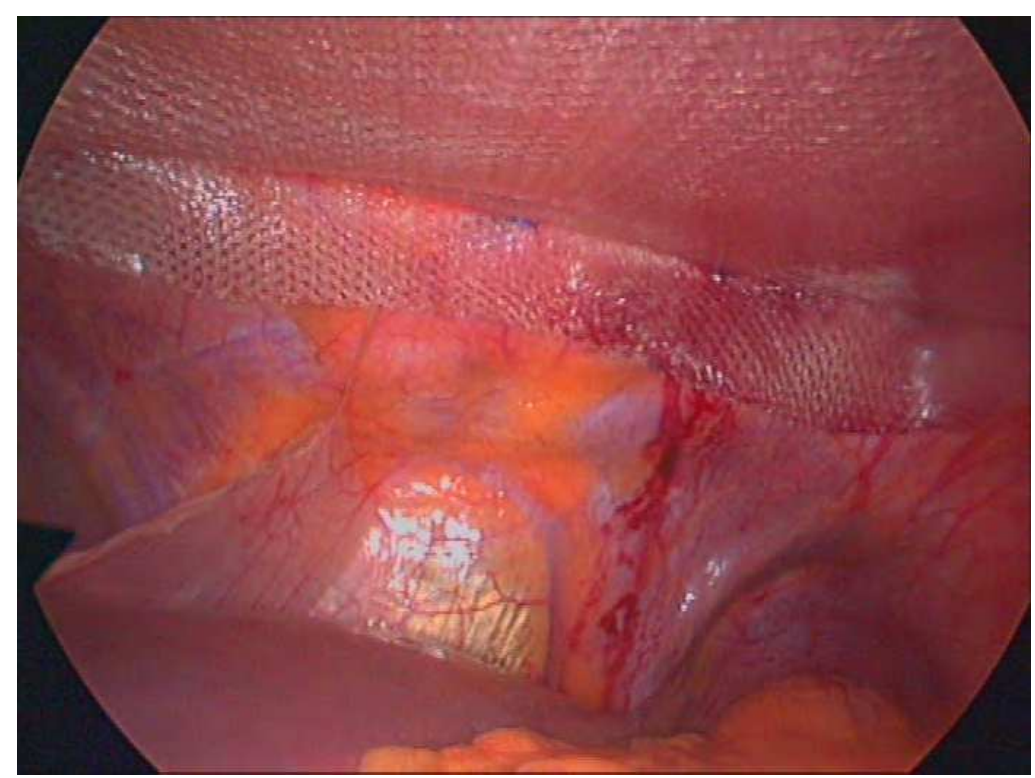

Fig. 5. Intraoperative laparoscopic view after Mesh implantation.

\section{Patient selection}

\subsection{General considerations}

In general we plan the laparoscopic approach for all patients with incisional hernia. Contraindications for laparoscopic hernia repair are the presence of anesthetic (severe pulmonary disease) or technical contraindications (eviscerated organs) or patients unwilling to undergo laparoscopic surgery.

\subsection{Large incisional hernia}

In our institution we prospectively evaluated 125 with a hernia diameter $\geq 5 \mathrm{~cm}$ among 428 patients undergoing incisional hernia repair. We demonstrated that laparoscopic repair of large incisional hernias is technical feasible and associated with less SSI and shorter hospital stay but a comparable recurrence rate as open hernia repair (Table 2) [11]. 


\begin{tabular}{cccc}
\hline & $\begin{array}{c}\text { Lap. group } \\
\mathbf{n = 6 9}\end{array}$ & $\begin{array}{c}\text { Open group } \\
\mathbf{n = 5 6}\end{array}$ & $\boldsymbol{P}$-Value \\
\hline SSI & $4(5.8)$ & $16(26.8)$ & 0.006 \\
Intestinal fistula & $0(0)$ & $1(1.8)$ & n.s. \\
Hospital stay (days) & $6(1-23)$ & $7(1-67)$ & 0.014 \\
Recurrence & $11(15.9)$ & $10(17.9)$ & n.s. \\
Return to work (weeks) & $3(0-50)$ & $6(0-28)$ & n.s. \\
Pain at follow-up (VAS) & $0.6(0-6)$ & $0.5(0-5)$ & n.s. \\
\hline
\end{tabular}

Values in parentheses are percentages unless indicated otherwise. * Values are median (range).

Table 2. Results of outcome parameters of large incisional hernia repair

\subsection{Incisional hernia after liver transplantation}

We showed that laparoscopic incisional hernia repair is feasible and safe even in patients under immunosuppressive therapy [12].

\section{Postoperative outcome}

\subsection{Conversion to open surgery}

The conversion rate to open surgery depends on the surgeons experience, the surgical skills, and intraoperative complications such as bowel lesions or bleeding. In the literature conversion to open surgery is mostly due to adhesions, with an overall conversion rate of $10-15 \%[12,13]$. However, complete adhesiolysis is very important especially in large incisional hernia to gain enough place for the mesh fixation and therefore to minimize the recurrence rate.

\subsection{Operation time}

There is a wide range in duration of the operation comparing laparoscopic and open incisional hernia repair. Most studies revealed that operation time in laparoscopic incisional hernia repair is longer compared to open surgery [12-14]. However, there was always a statistically difference in all these studies. Longer operation time can be explained with the learning curve in laparoscopy. Furthermore the fixation technique of the mesh can be time consuming especially in large incisional hernia repair. On the other hand there are some studies with no difference or even a shorter operation time in laparoscopic surgery $[15,16]$.

\subsection{Sugical site infections}

The definition of Surgical site infections (SSIs) according to the criteria developed by the Centers for Disease Control and Prevention include every SSI up to 30 days after the operation [17]. Infections are categorized as incisional (superficial or deep) infections or organ-space infections. Superficial SSIs involve only skin and subcutaneous tissue and exclude stitch abscesses. Deep SSIs involve deeper soft tissues at the site of incision. Organ- 
space SSIs are defined as infections in any organ or space. In laparoscopic incisional hernia repair the incidence of SSI is low. In a meta-analysis of 8 randomized controlled trials Forbes et al. showed a significant reduced risk of surgical site infections in laparoscopic incisional hernia repair compared to open surgery [18]. The extensive tissue dissection which is associated with the open approach explains the significant higher infection rate in open surgery. Mostly SSIs in laparoscopic surgery are superficial and can be treated conservatively. Mesh removal due to an surgical site infection is very rare [19].

\subsection{Enterotomy}

In general the mortality rate of laparoscopic incisional hernia repair is low with $0.05 \%$ [8]. The most serious complication during laparoscopic incisional hernia repair is enterotomy [8]. Enterotomy occurs during adhesiolysis or as a burning lesion with the electorcauter. Therefore we avoid electrocauterisation during adhesiolysis to prevent bowel lesions and perforation. The incidence of intraoperative bowel injuries has been reported to be $1.78 \%$ [20] A recognized enterotomy during the operation is associated with a mortality rate of $1.7 \%$ [20]. However, if the enterotomy is not recognized during the operation the mortality rate is increased up to $7.7 \%$ [20]. Enterotomy can be repaired by laparoscopic or open approach with similar outcome result [20].

\subsection{Enterocutaneous fistula}

Enterocutaneous fistula after intraperitoneal non-resorbable mesh implantation was first reported in by Kaufman et al. in 1981 [21]. An overview of the current literature shows that enterocutaneous fistula after incisional hernia repair is a rare complication and occurs in up to $1 \%$ [22]. There was no association of enterocutaneous fistula if the omentum was placed between the mesh and bowel or not. In cases of enterocutaneous fistula the mesh has to be resected partially around the fistula. Complete mesh removal is very rare and depends on the surgeons experience [23]

\subsection{Pain}

Lomanto et al. showed that there is no difference in the amount of pain comparing laparoscopic and open hernia repair at 24 and 48 hours postoperatively [24]. However, patients undergoing laparoscopic repair had significantly less pain at 72 hours compared to open surgery allowing earlier discharge and return to work [24].

The threshold for chronic pain is set at three months postoperatively according to the International Association for the Study of Pain [25]. There is no meta-analysis investigating chronic pain after laparoscopic incisional hernia repair. Postoperative pain after mesh fixation with transfascial sutures is likely due to nerve irritation or entrapmen [26]. There is a randomized controlled trial investigating pain comparing two different techniques of mesh fixation [26]. Postoperative pain following suture fixation was significantly higher at 6 weeks postoperatively and two patients suffered from nerve irritation at sites of sutures. However, after 6 months, no difference was seen between the two groups. Pain after mesh fixation with transfascial sutures is likely due to nerve irritation or entrapment and the relatively small distance between individual sutures used in this study. The significant reduction of pain between 6 weeks and 6 months post operation in these patients could be in response to desensitisation of entrapped nerve fibres or in response to resolution of local 
inflammation [26]. Asencio et al. showed in their study that $22 \%$ of the laparoscopic group and $7 \%$ of the open group reported significantly pain three months after the operation [13]. But all were pain free one year after the operation [13] . Therefore when pain persists a surgical revisions due to nerve irritation is not recommended earlier than 6 months. Alternatively a postoperative local injection of bupivacaine and steroids or removal of the offending suture is recommended [27].

\subsection{Recurrence rate}

Recurrence rate is one of the most important long-term outcome parameters in laparoscopic incisional hernia repair. Forbes et al. showed in their meta-analysis no difference in the recurrence rate between laparoscopic and open incisional hernia repair [18]. The pooled recurrence rate in the laparoscopic group was 3.4\% and in the open group $3.5 \%$ in this study. Such a low recurrence rate after either laparoscopic and open repair can be explained with a relatively short follow-up and the small size of the hernias [18]. A follow-up of at least three years is mandatory to evaluate correctly the real incidence of incisional hernia due to the fact that incisional hernia can occur up to 5 years after the operation. With such a long-term follow-up the incidence of recurrence has been reported to be up to $15-20 \%$ in laparoscopic and open repair $[11,13]$.

Two technical details can minimize the recurrence rate. First a sufficient overlap of the mesh and second the mesh fixation. We showed a significant decrease in horizontal mesh size after tack fixation (mean difference $-3.1 \% \pm 3.9 \%)$ versus fixation using sutures $(-0.1 \% \pm 2.3 \%$; $\mathrm{p}=0.018$ ) [26]. Mean vertical mesh size was not significantly different between the two groups: tack fixation $-2.8 \% \pm 6.1 \%$, suture fixation $-0.7 \% \pm 4.1 \%(\mathrm{p}=0.16)$. Mean mesh area in the tack fixation group was $-12 \%$ and in the suture fixation group $-2.9 \%$ at 6 months post operatively when compared to post-op day $2(p=0.061)$ [26]. Therefore a sufficient meshoverlap of the hernial orifice is mandatory in order to reduce recurrence rate.

Typical locations for hernia recurrences due to the mesh shrinkage are at the margin of the mesh as shown in Fig. 6. Because the risk to gain a second incisional hernia or a recurrent hernia along the full length of the incision, it is recommended to cover the whole length of the incision during the first operation.

\subsection{Seroma formation}

The retained hernia sac is responsible for seroma formation. Seroma formation is classified as a complication if it lasts more than 6 weeks after the operation. A randomized controlled trial of Olmi et al. showed an incidence of seroma formation of $7 \%$ [15]. In most cases no intervention is necessary. In cases of symptoms or if the seroma lasts longer than 8 weeks a drainage is recommended. Potentially a compression dressing over a period of 7 days may prevent seroma formation.

\subsection{Hospitalisation time}

Forbes et al. showed in their meta-analysis that duration of hospital stay is significantly shorter in laparoscopic incisional hernia repair compared to open surgery [18]. Less amount of pain [24] and a significantly lower rate of surgical site infections in laparoscopic repair [18] are reflected in a shorter hospital stay. Influence of shorter hospital stay on overall costs in laparoscopic hernia repair is discussed below. 


\subsection{Costs}

On the one hand operative costs of laparoscopic incisional hernia repair compared to open surgery are significantly higher due to expensive surgical tools in laparoscopy. On the other hand in hospital costs are significantly lower in laparoscopic surgery due to shorter hospital stay, lower infection rate and less postoperative pain. However, laparoscopic incisional hernia repair is associated with significant lower overall costs. Therefore laparoscopic incisional hernia repair is cost effective $[15,28]$.



Fig. 6. Intraoperative laparoscopic view of a recurrent hernia along the incision at the edge of the mesh. 


\section{Conclusion}

In conclusion laparoscopic incisional hernia repair is feasible and safe. Reduced SSI and reduced hospital stay are the major short term advantages associated with laparoscopy most likely as a consequence of reduced wound size $[18,27]$. Recurrence rate are comparable in laparoscopic and open incisional hernia repair [18].

\section{References}

[1] M. Korenkov and E. Neugebauer. (2001). Comments on the letter from S. Petersen and K. Ludwig concerning our paper "Classification and surgical treatment of the incisional hernia. Results of expert meeting." Langenbeck's Arch Surg 386:65-73. Langenbecks Arch Surg, Vol. 386, No. 4, pp.310-311,

[2] K. Cassar and A. Munro. (2002). Surgical treatment of incisional hernia. Br J Surg, Vol. 89, No. 5, pp.534-545,

[3] M. Mudge and L. E. Hughes. (1985). Incisional hernia: a 10 year prospective study of incidence and attitudes. Br J Surg, Vol. 72, No. 1, pp.70-71,

[4] J. Hoer, G. Lawong, U. Klinge and V. Schumpelick. (2002). [Factors influencing the development of incisional hernia. A retrospective study of 2,983 laparotomy patients over a period of 10 years]. Chirurg, Vol. 73, No. 5, pp.474-480,

[5] L. T. Sorensen, U. B. Hemmingsen, L. T. Kirkeby, F. Kallehave and L. N. Jorgensen. (2005). Smoking is a risk factor for incisional hernia. Arch Surg, Vol. 140, No. 2, pp.119-123,

[6] F. C. Usher. (1962). Hernia repair with Marlex mesh. An analysis of 541 cases. Arch Surg, Vol. 84, No. pp.325-328,

[7] V. Schumpelick, J. Conze and U. Klinge. (1996). [Preperitoneal mesh-plasty in incisional hernia repair. A comparative retrospective study of 272 operated incisional hernias]. Chirurg, Vol. 67, No. 10, pp.1028-1035,

[8] K. A. LeBlanc. (2005). Incisional hernia repair: laparoscopic techniques. World J Surg, Vol. 29, No. 8, pp.1073-1079,

[9] F. E. Muysoms, M. Miserez, F. Berrevoet, G. Campanelli, G. G. Champault, E. Chelala, U. A. Dietz, H. H. Eker, I. El Nakadi, P. Hauters, M. Hidalgo Pascual, A. Hoeferlin, U. Klinge, A. Montgomery, R. K. Simmermacher, M. P. Simons, M. Smietanski, C. Sommeling, T. Tollens, T. Vierendeels and A. Kingsnorth. (2009). Classification of primary and incisional abdominal wall hernias. Hernia, Vol. 13, No. 4, pp.407-414,

[10] J. Nieuwenhuizen, G. H. van Ramshorst, J. G. Ten Brinke, T. de Wit, E. van der Harst, W. C. Hop, J. Jeekel and J. F. Lange. (2011). The use of mesh in acute hernia: frequency and outcome in 99 cases. Hernia, Vol. No.

[11] A. Kurmann, E. Visth, D. Candinas and G. Beldi. (2011). Long-term follow-up of open and laparoscopic repair of large incisional hernias. World J Surg, Vol. 35, No. 2, pp.297-301,

[12] A. Kurmann, G. Beldi, S. A. Vorburger, C. A. Seiler and D. Candinas. (2010). Laparoscopic incisional hernia repair is feasible and safe after liver transplantation. Surg Endosc, Vol. 24, No. 6, pp.1451-1455, 
[13] F. Asencio, J. Aguilo, S. Peiro, J. Carbo, R. Ferri, F. Caro and M. Ahmad. (2009). Open randomized clinical trial of laparoscopic versus open incisional hernia repair. Surg Endosc, Vol. 23, No. 7, pp.1441-1448,

[14] U. Barbaros, O. Asoglu, R. Seven, Y. Erbil, A. Dinccag, U. Deveci, S. Ozarmagan and S. Mercan. (2007). The comparison of laparoscopic and open ventral hernia repairs: a prospective randomized study. Hernia, Vol. 11, No. 1, pp.51-56,

[15] S. Olmi, A. Scaini, G. C. Cesana, L. Erba and E. Croce. (2007). Laparoscopic versus open incisional hernia repair: an open randomized controlled study. Surg Endosc, Vol. 21, No. 4, pp. 555-559,

[16] M. C. Misra, V. K. Bansal, M. P. Kulkarni and D. K. Pawar. (2006). Comparison of laparoscopic and open repair of incisional and primary ventral hernia: results of a prospective randomized study. Surg Endosc, Vol. 20, No. 12, pp.1839-1845,

[17] (2004). National Nosocomial Infections Surveillance (NNIS) System Report, data summary from January 1992 through June 2004, issued October 2004. Am J Infect Control, Vol. 32, No. 8, pp.470-485,

[18] S. S. Forbes, C. Eskicioglu, R. S. McLeod and A. Okrainec. (2009). Meta-analysis of randomized controlled trials comparing open and laparoscopic ventral and incisional hernia repair with mesh. Br J Surg, Vol. 96, No. 8, pp.851-858,

[19] U. A. Dietz, L. Spor and C. T. Germer. (2011). [Management of mesh-related infections.]. Chirurg, Vol. 82, No. 3, pp.208-217,

[20] K. A. LeBlanc, M. J. Elieson and J. M. Corder, 3rd. (2007). Enterotomy and mortality rates of laparoscopic incisional and ventral hernia repair: a review of the literature. Jsls, Vol. 11, No. 4, pp.408-414,

[21] Z. Kaufman, M. Engelberg and M. Zager. (1981). Fecal fistula: a late complication of Marlex mesh repair. Dis Colon Rectum, Vol. 24, No. 7, pp.543-544,

[22] W. W. Vrijland, J. Jeekel, E. W. Steyerberg, P. T. Den Hoed and H. J. Bonjer. (2000). Intraperitoneal polypropylene mesh repair of incisional hernia is not associated with enterocutaneous fistula. Br J Surg, Vol. 87, No. 3, pp.348-352,

[23] S. Stremitzer, T. Bachleitner-Hofmann, B. Gradl, M. Gruenbeck, B. BachleitnerHofmann, M. Mittlboeck and M. Bergmann. (2010). Mesh graft infection following abdominal hernia repair: risk factor evaluation and strategies of mesh graft preservation. A retrospective analysis of 476 operations. World J Surg, Vol. 34, No. 7, pp.1702-1709,

[24] D. Lomanto, S. G. Iyer, A. Shabbir and W. K. Cheah. (2006). Laparoscopic versus open ventral hernia mesh repair: a prospective study. Surg Endosc, Vol. 20, No. 7, pp. 1030-1035,

[25] (1986). Classification of chronic pain. Descriptions of chronic pain syndromes and definitions of pain terms. Prepared by the International Association for the Study of Pain, Subcommittee on Taxonomy. Pain Suppl, Vol. 3, No. pp.S1-226,

[26] G. Beldi, M. Wagner, L. E. Bruegger, A. Kurmann and D. Candinas. (2010). Mesh shrinkage and pain in laparoscopic ventral hernia repair: a randomized clinical trial comparing suture versus tack mesh fixation. Surg Endosc, Vol. 25, No. 3, pp.749-755, 
[27] M. S. Sajid, S. A. Bokhari, A. S. Mallick, E. Cheek and M. K. Baig. (2009). Laparoscopic versus open repair of incisional/ventral hernia: a meta-analysis. Am J Surg, Vol. 197, No. 1, pp.64-72,

[28] G. Beldi, R. Ipaktchi, M. Wagner, B. Gloor and D. Candinas. (2006). Laparoscopic ventral hernia repair is safe and cost effective. Surg Endosc, Vol. 20, No. 1, pp. 92-95, 


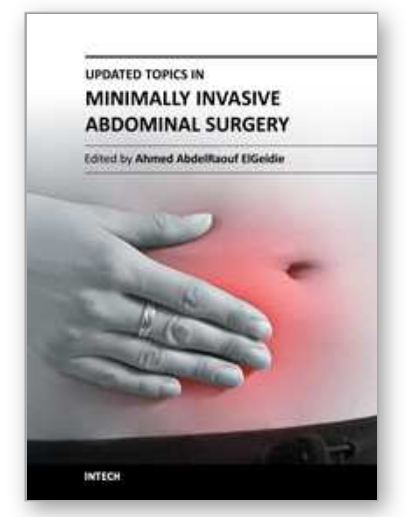

\author{
Updated Topics in Minimally Invasive Abdominal Surgery \\ Edited by Prof. Ahmed Elgeidie
}

ISBN 978-953-307-773-4

Hard cover, 246 pages

Publisher InTech

Published online 14, November, 2011

Published in print edition November, 2011

Updated topics in minimally invasive abdominal surgery provides surgeons interested in minimally invasive abdominal surgery with the most recent techniques and discussions in laparoscopic surgery. This book includes different topics covering a big variety of medical conditions with up-to-date information. It discusses many controversies in a clear and user-friendly manner. This book is made for young junior surgeons in training and also senior surgeons who need to know the most recent work in the field of laparoscopy. To make the material easily digestive, we provided the book with many figures and illustrations for different procedures and technical pearls.

\title{
How to reference
}

In order to correctly reference this scholarly work, feel free to copy and paste the following:

Anita Kurmann and Guido Beldi (2011). Laparoscopic Incisional Hernia Repair, Updated Topics in Minimally Invasive Abdominal Surgery, Prof. Ahmed Elgeidie (Ed.), ISBN: 978-953-307-773-4, InTech, Available from: http://www.intechopen.com/books/updated-topics-in-minimally-invasive-abdominal-surgery/laparoscopicincisional-hernia-repair

\section{INTECH}

open science | open minds

\section{InTech Europe}

University Campus STeP Ri Slavka Krautzeka 83/A 51000 Rijeka, Croatia Phone: +385 (51) 770447

Fax: +385 (51) 686166 www.intechopen.com

\section{InTech China}

Unit 405, Office Block, Hotel Equatorial Shanghai No.65, Yan An Road (West), Shanghai, 200040, China 中国上海市延安西路65号上海国际贵都大饭店办公楼 405 单元 Phone: +86-21-62489820

Fax: $+86-21-62489821$ 